\title{
RELAÇÕES DE GÊNERO E EDUCAÇÃO: UMA POLÍTICA CONSTRUÍDA NA (DES) IGUALDADE
}

\author{
GENDER RELATIONS AND EDUCATION: A POLICY CONSTRUCTED ON (IN) \\ EQUALITY
}

\author{
Luciene Celina Cristina Mochi ${ }^{1}$ \\ Universidade Federal de Juiz de Fora - UFJF
}

\begin{abstract}
Resumo
$\mathrm{O}$ artigo analisa as relações existentes entre igualdade/desigualdade como possibilidade política e afirmativa de se perceber as diferenças não como modos assimétricos de separação, mas como meios de promover democracia na educação escolar. A instituição educativa é um sistema social e exatamente por isso é repleto de pluralidades e desigualdades que, quando trabalhadas a partir da perspectiva do reconhecimento das diferenças como possíveis, deixam o lugar de 'não iguais' para ocuparem o lugar de 'pertencimento'. Espera-se que o texto possa contribuir para o entendimento das práticas educacionais como ferramentas para a mediação entre os conhecimentos produzidos historicamente pela escola e a relação com as desigualdades encontradas no seu espaço educativo, promovendo visibilidade para as múltiplas relações existentes no cotidiano escolar especialmente, para o reconhecimento da cidadania.
\end{abstract}

Palavras-chave: Desigualdades e Diferenças; Relações de Gênero; Educação Escolar.

\section{Abstract}

The article analyzes the relationship between equality/inequality as a political and affirmative possibility of perceiving differences not as asymmetrical modes of separation, but as means of promoting democracy in school education. The educational institution is a social system and precisely because of this it is full of pluralities and inequalities that, when worked out from the perspective of recognizing differences as possible, leave the place of 'not equal' to occupy the place of 'belonging'. It is hoped that the text can contribute to the understanding of educational practices as tools for mediation between the knowledge produced historically by the school and the relation with the inequalities found in its educational space, promoting visibility for the multiple relationships existing in the daily school, for the recognition of citizenship.

Keywords: Inequalities and Differences; Gender Relations; School Education.

\footnotetext{
${ }^{1}$ Pedagoga. Doutoranda no Programa de Pós-Graduação em Educação da Universidade Federal de Juiz de Fora/MG. Mestra em Ciências Sociais pela Universidade Estadual de Maringá/PR (UEM/2016). Especialista em Educação Especial com ênfase em Altas Habilidades/Superdotação e Transtornos Globais do Desenvolvimento (2008). Graduada em Artes Cênicas licenciatura para o Teatro (PARFOR/UEM/2016) e graduada em Pedagogia pela Faculdade de Jandaia do Sul (FAFIJAN/2002).
} 


\section{INTRODUÇÃO}

Debater desigualdade e diferença nas relações de gênero no contexto escolar pode contribuir para a compreensão das relações sociais existentes com os processos de exclusão social e os efeitos do aprofundamento das desigualdades decorrentes das transformações sociais e econômicas em curso sobre a construção da cidadania no Brasil.

Como ponto de partida, o presente trabalho ${ }^{2}$ propõe entrelaçar a sociologia da educação como ferramenta possível para análise capaz de transformar e de compreender o caráter conceitual e crítico acerca da educação, assim como compreender os reflexos desta para a cultura e sociedade, pois "a sociologia encontra-se precisamente no terreno por excelência da denegação do social” (apresentam BOURDIEU, 2007, p. 17).

Em meio às discussões teóricas, -se também, elementos e propostas de reflexões, destinadas a facilitar a compreensão sob o ponto de vista das desigualdades por meio da interseccionalidade, que é caracterizada pelo entrecruzamento de categorias como, classe, raça, gênero e orientação sexual. O objetivo está centrado em tecer alguns dos possíveis caminhos para repensar a igualdade e desigualdade como janelas para 0 entendimento das inúmeras formas de opressão e exclusão existentes no espaço escolar.

A escola contribui muito para o desenvolvimento social de suas/seus alunas e alunos, porém, em tempos de tentativas de retrocesso e perdas das garantias essenciais no atual campo político brasileiro, outras formas de se fazer escola são demandadas, como por exemplo, lidar com desigualdade e diferenças como possibilidades afirmativas, posicionando visibilidade para as mais variadas formas de ser e existir como seres humanos que possuem diferenças interpessoais.

O artigo está dividido em três seções. Na primeira, desenvolvo pressupostos a respeito das discussões sobre as relações de gênero no espaço escolar que separam de modo binário, o que é próprio para meninas e meninos. Essa divisão determina relações de apreciação, de valorização e de hierarquização distintas para alunas e alunos. Para adensar esse debate, serão utilizadas as contribuições da historiadora feminista Joan Scott (1985; 2005). Na segunda seção, apresento argumentos de Amartya Sen (2011) e Pierre Bourdieu (1999; 2007) para debater sobre desigualdade na educação a partir das relações de gênero. Ainda que as teorias defendias por Amartya Sen e Bourdieu não

\footnotetext{
${ }^{2}$ Uma versão anterior deste artigo foi elaborada para a disciplina de doutorado ministrada pelo professor Dr. Eduardo Magrone no primeiro semestre de 2017, a quem agradeço a correção e essenciais contribuições. Me manifesto evidentemente, como única responsável pelas lacunas e omissões contidas no texto.
} 
sejam intercambiáveis, existe uma conexão entre os conceitos que ambos defendem a respeito de desigualdades. $\mathrm{E}$, por último, haverá o debate sobre a experiência escolar como fundamental para se promover o reconhecimento das pluralidades e a percepção das diferenças como possibilidades afirmativas para o enfrentamento das variadas violências e discriminações nos contextos escolares, a fim de construirmos uma escola livre de racismo, sexismo e LGBTfobia.

\section{DESIGUALDADE E ESCOLA: QUAL O LUGAR DO GÊNERO?}

A feminista Joan Scott (1985, p. 31) argumenta que gênero "é um elemento constitutivo de relações sociais baseado nas diferenças percebidas entre os sexos" e compõe a primeira ordem de significados das relações de poder. O gênero pode ser definido por meio das identidades sociais, dos discursos, através da classificação dos corpos e, consequentemente, das práticas sociais. Em O enigma da igualdade (2005) Scott argumenta que se posicionarmos igualdade e diferença como conceitos assimétricos, polarizados, perderemos o ponto de suas interconexões, uma vez que igualdade e diferença, são elementos característicos das relações sociais e, sendo assim, "reconhecer e manter uma tensão necessária entre igualdade e diferença, entre direitos individuais e identidades grupais, é o que possibilita encontrarmos resultados melhores e mais democráticos" (SCOTT, 2005, p. 12).

A escola possui um terreno marcado por disputas e tensões de poder. Isso se dá, principalmente, pela pluralidade de pessoas que transitam em seus corredores. No ambiente escolar, as diferenças são representadas por meio de inscrições e signos que demarcam classe, gênero, raça e sexualidades. De todo modo, é também dentro do ambiente institucionalizado, tanto no desenvolvimento didático, quanto no decorrer das atividades socializadoras, que determinadas relações de apreciação, de valorização e de hierarquização são apreendidas socialmente e, por sua vez, são aprendidas ao longo da vida, dependendo da relação do sujeito com determinada cultura.

A legitimação do gênero como assimétricas e desfavoráveis para as mulheres ou determinados grupos em relação a outros atua de variadas maneiras. Pierre Bourdieu (2007), por exemplo, revelou que a existência opositora entre masculino e feminino determinam posições específicas de acordo com práticas e esquemas individuais e/ou de determinados grupos em detrimento de outras/os. O "habitus" (BOURDIEU, 2007, p. 198) é um conjunto de esquemas individuais que são socialmente estruturados e adquiridos por meio das experiências práticas do cotidiano. Nossa cultura, nosso modo de falar e de 
se expressar, encontra-se repleto de expressões que mobilizam esse conceito. $O$ habitus não é algo imaterial ou conceito em que se possa imobilizar de maneira imperativa para dizer que o mundo real está mais próximo ou mais afastado deste conceito. No conceito de habitus, reside importante contribuição que Bourdieu (2007) adiciona ao pensamento sociológico, e esse conceito pode ser utilizado como instrumento que possibilita pensar as relações existentes na escola como "condicionamentos sociais exteriores" que são internalizados pelo agente e, assim, adaptam as subjetividades das/os agentes. Como exemplo disso, nas escolas, temos as filas para meninos e para meninas, temos as atividades de Educação Física e recreio específicas e diferenciadas para meninos e para meninas. Essa separação do espaço ocupado (reservado) para meninas e para meninos demarca incentivos que representam o cerceamento dos corpos e dos comportamentos, o que pode gerar, consequentemente, divisão dos aspectos fundamentais da criatividade e da autonomia.

Outros signos, como, por exemplo, ser o menino considerado com maior dificuldade de comportamento; as meninas consideradas as que possuem letra mais uniforme e organização com os materiais escolares. Esses exemplos podem ser chamados de naturalização binária, em que comportamentos e sexualidades são designadas a partir da categoria "macho" e "fêmea".

Em busca de uma suposta manutenção de homogeneidade, a educação dita gostos, regras e uma lista de "certo" x "errado" no comportamento das crianças, o que gera, de fato, separação, exclusão e subordinação. Exclusão, porque, ao perceber que não consegue se enquadrar nos parâmetros binários e heterossexistas vivenciados na escola, alunas e alunos podem se sentir não representadas/os e, assim, estar em constante não-lugar. Subordinação, porque o esforço para se adequar às normas e padrões das relações de gênero causam, consequentemente, atitudes subordinadas ao que é considerado natural/normal, no que se refere à heterossexualidade como norma e, por último, separação de modos e comportamentos considerados próprios para meninas em detrimento dos meninos.

O habitus é resultado das práticas sociais de determinado campo social, e a escola é, por excelência, um campo social. Para Bourdieu (2007), a relação existente entre indivíduo e sociedade oferece categorias simultaneamente conectadas com base em comportamentos orquestrados. Desta forma, a relação entre o que é individual e o que é coletivo com base em comportamentos "esperados" implica afirmar que a subjetividade e o comportamento pessoal fazem parte da coletividade orquestrada pelo habitus, cuja a 
prática social só se dá a partir da análise dos grupos em que estão inseridas/os em um determinado contexto, como a escola, por exemplo, em que as divisões e os marcadores da diferença como assimetrias podem reproduzir no ambiente escolar, atitudes e comportamentos mais aceitas/os do que outras/os, assim como acontece nas regras de determinada brincadeira infantil denominada de "pertence, não pertence 3 ".

Essa pertença, perpetuada no ambiente da escola, traz, ou melhor, carrega a insígnia de que alunas/os devem possuir uma característica de aprendizagem e constituição social comum, ou seja, uma possível e complexa exigência de estandardização para todas/os. Essa atitude de homogeneização, engendrada pela escola, pode, na verdade, "demandar um tratamento bastante desigual em favor dos que estão em desvantagem" (SEN, 2001, p. 29). De acordo com o autor, "o efeito de ignorarse as variações interpessoais pode ser, na verdade, profundamente não igualitário" (SEN, 2001, p. 29). Expostas às influências do campo escolar, começa-se a assumir uma identidade que foge ao aprendizado curricular e as avaliações pedagógicas, pois gênero, orientação sexual, classe e raça são indissociáveis deste processo de ensino, uma vez que "existe dentro dos espaços escolares, dos corredores às salas de aula, uma multiplicidade de formas culturais que coexistem" (MOCHI; LEITE, 2015, p. 71).

Lidar com as desigualdades ${ }^{4}$, com os diferentes processos escolares, com as diferentes possibilidades de aprender a ser e existir são constantes desafios que a escola, em especial a escola pública, vem desenvolvendo cotidianamente. Scott afirma que as diferentes identidades de grupo são fatos da existência social e que simplesmente ignorar a existência das contradições existentes nas identidades individuais e entre grupos é perceber a diferença como fator de separação e, por consequência, exclusão. Para ela, "faz mais sentido perguntar como os processos de diferenciação social operam [...]" (SCOTT, 2005, p. 29) e a, com base nisso, "desenvolver análises de igualdade e discriminação que tratem as identidades não como entidades eternas, mas como efeitos de processos políticos e sociais" (SCOTT, 2005, p. 29)

\footnotetext{
${ }^{3}$ Atividade lúdica utilizada nas séries iniciais do Ensino Fundamental para trabalhar conjuntos de classificações, como números, palavras, símbolos e objetos. Para saber mais: BONZANINI, LC.; BASSOI, TS. Os professores e o ensino de frações no $2^{\circ}$ ciclo do Ensino Fundamental. In: BRANDT, CF.; MORETTI, MT. (Orgs.). Ensinar e aprender matemática: possibilidades para a prática educativa [online]. Ponta Grossa: Editora UEPG, 2016, pp. 145-159. ISBN 978-85-7798-215-8.

${ }^{4} \mathrm{O}$ conceito de desigualdade pode ser entendido como hierarquia social que favorece e/ou dificulta determinados grupos a acessarem serviços públicos como educação, saúde, lazer e demais serviços. Para este trabalho, utilizo o conceito de "desigualdade e igualdade" para questionar as divisões realizadas nos contextos escolares de acordo com o que é próprio para meninas e para meninos, demandando tratamento desigual nas atividades escolares.
} 
Como saber institucional, e, por meio de documentos oficiais que regulam a educação brasileira como a Lei de Diretrizes e Bases da Educação Nacional (BRASIL, 1996), o acesso e a permanência das crianças na escola é garantia constitucional, confirmando no plano legal, a democratização do ensino. Porém, historicamente, no Brasil, o tema da exclusão social se assenta desde a relação entre colonizador e colonizada/o, com a exploração de riquezas praticada pelos comerciantes e espoliadores e, para somar com este começo da nossa república, temos o processo de escravidão que apreendeu a condição humana à elite e transformou as/os negras/os e indígenas em atestados de riqueza e detenção de poder. Compreender essa particularidade da história brasileira ajuda-nos a entender os desafios da escola pública em lidar com as desigualdades, de maneira a construir na diferença uma possibilidade de crescimento e políticas públicas que sejam capazes de proporcionar crescimento educacional mais equânime para alunas e alunos e, assim, construir a universalidade de condição humana, estendendo-a a todas/os as/os brasileiras/os.

A cultura patrimonial brasileira predominante estrutura a sociedade por classes sociais, divididas entre quem necessita acessar serviços públicos e quem não precisa. $\bigcirc$ capitalismo alimenta-se da violência e das discriminações na intersecção de gênero, raça e orientação sexual. O acesso a serviços sociais públicos como um direito é precário, com a justificativa de que algumas/uns tem mais direitos que as/os outras/os. Isso estimula as desigualdades sociais. Desta forma, o acesso (e a permanência) a serviços como saúde e educação de qualidade não são integrados pela cultura patrimonial.

A cultura patrimonial não incorpora padrões básicos e universais de cidadania. A inclusão dos que menos tem é circunstancial, casuística, meritocrática e seletiva. Este tipo de sociedade não incorpora uma cobertura universal dos riscos sociais; seu patamar, como diria Smith, é do risco individual (SPOSATI, 1998, p. 5).

O Estado brasileiro consolida uma dada concepção de inclusão, não assegurando a garantia de direitos sociais em suas ações: evidencia as atenções sociais como concessões partilhadas com a filantropia da sociedade e não assumidas como responsabilidade pública. Trata-se de uma maneira seccionada ou seletiva da inclusão social (SPOSATI, 1998). Segundo a autora, a relevância da questão cultural intensifica a tese de que "não se avançará na consolidação das garantias sociais enquanto a sociedade civil não encaminhar um projeto solidário nessa direção" (SPOSATI, 1998, p. 6). Para saber lidar com as diferenças e tratamento igualitário entre os gêneros de maneira não sectária e naturalizada, precisamos debater para além da categoria classe, 
mesmo compreendendo que a exigência de padrões mínimos é imprescindível para a dignidade humana. Certamente, Estado e governo, no que diz respeito à gestão administrativa, devem consolidar e regulamentar tais garantias. No entanto, sua efetivação é resultante de determinantes sociais, como, por exemplo, a heteronormatividade compulsória.

Desde o período colonial até a atualidade, a busca por equidade vem sendo objeto de discussão entre estudiosas feministas, preocupadas com as categorias da divisão sexual do trabalho e, por conseguinte, com o desenvolvimento político, econômico e social do Brasil. Os temas abrangendo as desigualdades, a injustiça, LGBTfobia e o autoritarismo fazem parte, tanto da esfera pública quanto da privada da história brasileira, estabelecendo um consenso no fato de que os paradoxos entre inseridas/os/ marginalizadas/os, dirigentes/dirigidas/os e cidadãs/os foram levados ao extremo. Nem mesmo a instituição da República mostrou-se suficientemente capaz de universalizar os direitos, aspecto atual de retrocessos na política brasileira. Diversas são as explicações para a desigualdade encontrada em nossa sociedade, porém, a herança da escravidão é um sério componente racista e segregacionista que continua hierarquizando os corpos, as classes e as sexualidades. Para a pesquisadora Eliane Cavalleiro, "o silêncio que atravessa os conflitos étnicos na sociedade é o mesmo que sustenta o preconceito e a discriminação no interior das escolas" (2017, p. 98).

A falta de uma política democrática na sociedade brasileira dificulta o entendimento do conflito e, ao invés de saber lidar com as diferenças como possiblidades de crescimento, utiliza a "tolerância" como um fator de acirramento de conflitos. Em uma sociedade democrática e socialmente dividida por categorias de raça, classe e relações de gênero, o espaço público é marcado por disputas políticas e, consequentemente, pela conservação de seus respectivos interesses. Para Scott (2005), a identidade é dialógica, variável e faz parte de um processo contínuo e complexo de transformações, cuja a política pode ser compreendida como "[...] negociação do impossível, a tentativa de chegar a soluções que - em sociedades democráticas - aproximam os princípios da justiça e da igualdade [...]" (SCOTT, 2005, p. 29). Neste caso, por exemplo, a heterossexualidade e o pragmatismo religioso tornam-se bandeiras políticas, evocando o direito a ter "direitos", deixando à margem, todas as outras possibilidades de ser e existir, contribuindo para o aprofundamento das desigualdades gestada na diferença como marcadora posicional e não como possibilidades de outras identidades, "as afirmações 
sobre diferença também dependem de uma cadeia, em geral oculta, de declarações negativas sobre outras identidades" (SILVA, 2013, p. 75).

\section{(RE)EXAMINANDO IGUALDADE E DIFERENÇA: CONTRIBUIÇÕES DE AMARTYA SEN}

No livro Desigualdade Reexaminada, Amartya Sen (2001) discorre sobre o que significa igualdade, questionando "igualdade de quê?" (SEN, 2001, p. 34). Essa questão atravessa todo o texto desenvolvido pelo autor, numa abordagem metodológica utilizada para questionar a desigualdade social e explorar a análise dos arranjos sociais.

A ideia de igualdade possui, segundo o autor, dois tipos de diversidade, o da heterogeneidade dos seres humanos e as inúmeras multiplicidades de variáveis relativas à igualdade que podem ser avaliadas. Ao questionar a igualdade em relação às diversidades humanas, de classe, de raça, de gênero, encontramos importante contribuição de Amartya Sen (2001). O autor questiona que inúmeras são as demandas dos indivíduos e que essas variáveis precisam ser vistas e analisadas dentro do contexto de outras demandas por igualdade e não analisadas separadamente de outras questões. Amartya Sen (2001) propõe-nos uma visão de funcionamentos que ultrapassa a visão do "ter". Essa prática tem relação direta de intercâmbio com a ética por meio da cooperação interdiscursiva entre o raciocínio ético e o raciocínio econômico.

Ao pensar na constante obsessão da escola por homogeneidade e, consequentemente, a percepção assimétrica da diferença, o que é próprio para meninos e para meninas, o conceito binário de gênero, não ignorando os aspectos biológicos, mas, sobretudo, pensar nas relações de gênero como construção histórica que é produzida sobre diferentes variáveis, compreendemos que o debate sobre as relações de gênero nas escolas, necessitam serem pautadas no campo social, pois é nele que se constroem e se (re)produzem as relações desiguais entre as pessoas. De acordo com o autor, a "heterogeneidade das pessoas resulta em divergência na avaliação da igualdade em termos de variáveis diferentes. Isto acrescenta significado à questão central da obra do autor: igualdade de quê?" (SEN, 2001, p. 29).

Quando a busca pela igualdade é examinada isoladamente de outras questões importantes e relevantes da vida das pessoas, corre-se o risco de termos uma avaliação distorcida do conceito de igualdade. Portanto, ao focarmos no slogan "igualdade" podemos tê-la como uma ideia "contrariada por diversidades de dois tipos distintos: (1) a heterogeneidade básica dos seres humanos, e (2) a multiplicidade de variáveis em cujos termos a igualdade pode ser julgada" (SEN, 2001, p. 29). 
O autor defende que as capacidades dos indivíduos é que devem ser igualadas, como, por exemplo, a igualdade de oportunidades que valoriza a liberdade das pessoas em fazer escolhas, porém, como já vimos com Bourdieu (2007), a ideia de habitus contesta o poder de escolha das pessoas. Talvez seja este um ponto crítico a ser questionado na obra de Amartya Sen, pois a capacidade de escolha faz parte de outras variáveis e imbricações, como, por exemplo, o desenvolvimento de um habitus específico que é resultado de usos e práticas sociais. Por outro lado, existe também confluência entre os dois autores no que se refere à ideia de que os modos e usos dos bens sociais não são iguais para cada pessoa. A esse respeito, o discurso sobre a suposta igualdade "tende frequentemente a desviar a atenção destas diferenças" (SEN, 2001, p. 29). Ao ignorarmos as diferenças interpessoais já estamos fazendo distinção e, consequentemente, demandando "tratamento bastante desigual em favor dos que estão em desvantagem" (SEN, 2001, p. 30).

As relações de gênero podem ser consideradas como um dos eixos centrais para a organização social das nossas experiências no mundo. As desigualdades que atendem padrões binários de gênero definem as posições relativas de homens e mulheres, como na divisão sexual do trabalho, do cuidado das crianças majoritariamente destinado às mulheres e no uso desigual do tempo na vida privada para mulheres e homens. Ainda que por si só o gênero não faça essa separação isoladamente, mas ele perpassa a classe, raça e a sexualidade.

Por isso, é importante discutir relações de gênero na escola. Para além do respeito às diferenças existentes em cada indivíduo, valoriza-se que na diferença podemos ser mais habilitadas/os a desenvolver nossas capacidades, não a partir das desigualdades, mas além delas. Igualdade não é o contrário da diferença, mas um processo de demarcação social cujas relações definem e dão contornos às formas de diferença por meio dos sistemas classificatórios entre as pessoas, podendo, assim, dividir essa população em pelo menos dois grupos opostos: Eu/tu - Nós/elas/eles. Os sistemas classificatórios partem do princípio da diferença, à medida que nos classificamos como Nós, paralelamente, apontamos Elas/es como negativas em relação ao que Nós não somos. Os sistemas sociais simbólicos produzem as estruturas classificatórias que causam uma certa ordem às diferenças fundamentais da vida social entre "nós e eles", "fora e dentro", "certo e errado", "moral e imoral", "masculino e feminino", "heterossexual e homossexual", que estão no cerne dos sistemas identitários da significação de cultura. E o que dizer sobre a(s) identidade(s) de gênero? Amartya Sen (2001) observa que: 
Se toda pessoa fosse parecidíssima com cada uma das outras, uma causa importante dessas dissonâncias desapareceria. Se os rankings de igualdade em espaços diferentes coincidissem, seria então menos importante dispor de uma resposta clara para a questão: igualdade de quê? A diversidade generalizada dos seres humanos acentua a necessidade de lidar com a diversidade de foco na avaliação da igualdade (SEN, 2001, p. 31).

Contudo, Amartya Sen trata da noção de "capacidades" relacionada à ideia de liberdade efetiva, o que resulta dos funcionamentos, ou seja, da capacidade de as pessoas gerirem o que desejam. A exclusão e as desigualdades sociais anulam ou diminuem a possibilidade de o indivíduo de ter sua liberdade efetiva na sociedade capitalista, em que a distribuição da riqueza está na posse de um número cada vez menor de pessoas, como mostra o estudo realizado em 2017 pela Oxfam sobre desigualdade no Brasil. Segundo reportagem do jornal El País, seis (06) brasileiros concentram a mesma riqueza que a metade da população mais pobre. O levantamento ${ }^{5}$ revela "que os $5 \%$ mais ricos detêm a mesma fatia de renda que os demais 95\% da população" (El País, 2017, $\mathrm{s} / \mathrm{p})$. Essa questão se relaciona à crítica que Amartya Sen endereça à falta de moralidade na economia como ética e racionalidade, a "avalição das demandas de igualdade tem de ajustar-se à existência de uma diversidade humana generalizada" (SEN, 2001, p. 29). O autor nos auxilia a pensar na diversidade como possibilidades de crescimento humano e social, "é porque somos tão profundamente diversos que a igualdade num espaço com frequência resulta em desigualdades de espaços" (SEN, 2001, p. 185). Por isso, o autor propõe uma cooperação interdiscursiva entre o raciocínio ético e o raciocínio econômico.

\section{(DES)IGUALDADES NA ESCOLA: POR ONDE PODEMOS COMEÇAR?}

Ao pensarmos na escola, imaginamos um local de multiplicidades, diversidade de conjugações familiares, diferentes culturas e habitus (BOURDIEU, 2007), as quais envolvem uma variedade de estratégias de ensino e aprendizagem. Dentro da escola, as diferenças transitam diariamente, por isso um bom começo seria lidar com as diferenças como possibilidades de crescimento contínuo e não como princípio de algo que falta.

Embora existam diferentes formas de desigualdades, não podemos reduzi-las a uma única raiz, pois "algumas desigualdades são mais estruturantes da ordem social que outras; e também que algumas se manifestam com violência mais aberta do que outras"

\footnotetext{
${ }^{5} \mathrm{O}$ estudo também revela a desigualdade de gênero e raça, demonstrando que a desigualdade salarial entre homens e mulheres e entre brancos/as e negras/os (para menos). Para maiores aprofundamentos acessar o relatório da Oxfam, "a diferença que nos une", disponível para download em: https://www.oxfam.org.br/sites/default/files/arquivos/Relatorio A distancia que nos une.pdf
} 
(MIGUEL, 2016, p. 13). A título de exemplo das desigualdades que são mais violentas que outras temos os dados de pesquisa recentemente realizada que aponta que no "Brasil, um homossexual é morto a cada 25 horas" (ALVIM, 2017, s/p). Ainda sobre a desigualdade que mata, o último relatório da Associação Internacional de Lésbicas, Gays, Bissexuais, Transgêneros e Intersexuais (ILGA) informou que é também o Brasil o primeiro lugar em homicídios por homofobia nas "Américas, com 340 mortes por motivação homofóbica em 2016" (DINIZ, 2017, s/p). O grupo de pesquisa Lesbocídio - As histórias que ninguém conta, lançou neste ano de 2018, o primeiro dossiê sobre lesbocídio no Brasil, que conta com levantamento de dados sobre a morte de lésbicas nos anos de 2014 a 2017. Apesar da ausência de informações, silenciamento e invisibilidade sobre a vida e mortes de lésbicas, o trabalho apurou o excessivo aumento de assassinatos no Brasil, "de 14 casos registrados em 2014, o número alcançou em 2017, 35 casos registrados, evidenciando um aumento de $150 \%$ em apenas quatro anos [...]" (PERES; SOARES; DIAS, 2018, p. 81).

Essa é uma realidade que não está fora dos muros da escola. A educação não é fenômeno puramente técnico-pedagógico de mediação do conhecimento científico elaborado. Ela também é constituída de disputas políticas e ideológicas. Essas disputas são marcadas por uma sociedade de classes, atravessada por desigualdades sociais, econômicas e culturais que se estabelecem dentro das relações humanas. Assim, 0 ato político de "educar" está intimamente ligado a concepções de democracia e de sociedade, como nos assevera Dermeval Saviani (2003, p. 84): "toda prática educativa, como tal, possui uma dimensão política assim como toda prática política possui, em si mesma, uma dimensão educativa". Estar atenta ou não para as desigualdades é ato político que pode (e deve) ser realizado pela escola, considerando que o próprio silêncio em relação às diferenças individuais e familiares de alunas e alunos diz muito sobre o que pode ou o que não pode ser democratizado (falado) no ambiente escolar.

Desse modo, para além do conhecimento científico elaborado e da democratização do ensino, romper as práticas excludentes e sectárias de modos de ser e se comportar socialmente são competências que precisam ser reelaboradas e desenvolvidas pela escola, como por exemplo, as discussões teóricas sobre gênero, classe, raça e sexualidade. A defesa de uma educação pública, laica e com qualidade, que seja ancorada no direito às chamadas "minorias" não normativas, grupo este que frequentemente é excluído do acesso e permanência na escola e, consequentemente, excluídos também do acesso aos conhecimentos historicamente construídos. 
A escola possui papel protagonista no enfrentamento às violências e não apenas um mero reflexo de reprodução social. É na escola que temos a chancela do conhecimento científico e é também nos bancos escolares que situações de discriminação e práticas ideológicas são nutridas como "naturais". A educação "é um dos elementos que tocam de maneira mais radical na crise da relação entre políticas educacionais e desigualdades" (ARROYO, 2010, p. 1399). A mediação entre educação e desigualdades precisa ser retomada pela escola, pois essa relação "foi desfigurada e soterrada nos escombros de relações de mercado, de educação e padrão mínimo de qualidade, de currículos por competências, gestão e avaliações de resultados" (ARROYO, 2010, p. 1384). Ainda para o autor, "as desigualdades não só continuam, mas se aprofundam e vitimam milhões de famílias e alunos(as)" (p. 1384).

A escola trabalha por meio do viés das desigualdades, agindo como seletora "natural" de assimetrias entre as/os alunas/os, e, ao passo que desenvolve essa busca pela homogeneidade, ela legitima e contribui para a manutenção das desigualdades sociais. Para Bourdieu (1999, p. 21), o território escolar "[...] é um dos fatores mais eficazes de conservação social, pois fornece a aparência de legitimidade às desigualdades sociais, e sanciona a herança cultural e o dom social tratado como dom natural [...]". Pensando nas assimetrias vinculadas pela escola nos complexos padrões de igualdade gestados como política democrática, o autor Luis Felipe Miguel (2016, p. 12) ajuda-nos a pensar:

Riqueza, classe, gênero e raça, bem como outras assimetrias, vinculadas a questões como a sexualidade ou a presença de deficiências, criam padrões complexos de desigualdade, que se expressam na esfera política. É com essa complexidade que a democracia deve lidar, respondendo a duas questões complementares: em que medida a vigência de tais desigualdades compromete a própria existência da democracia, isto é, até que ponto podemos continuar falando em democracia quando as instituições políticas não apenas convivem com, mas também reproduzem tanta desigualdade? E de que maneira a democracia pode contribuir para reduzir as desigualdades sociais, se é que pode?

Como instituição social que disputa hegemonia, a escola, ao mesmo tempo que busca a democratização do ensino e aprendizagem, busca também atender aos interesses da classe dominante que é alicerçada em desigualdades e hierarquias que privilegiam a heterossexualidade como única prática possível de existência. Temos então um caminho a ser percorrido e também uma mudança de ideia sobre a desigualdade, à medida que compreendemos o quanto grupos distintos sofrem atravessamentos normalizadores de comportamentos e sexualidades. 
É razoável pensar que o racismo e o capitalismo definem mais características estruturais da sociedade brasileira contemporânea do que a homofobia, mas, ao mesmo tempo, entre todos os grupos em posição subalterna, são gays, lésbicas e transgêneros aqueles que provavelmente sofrem as formas mais declaradas e acintosas de discriminação e violência (MIGUEL, 2016, p.13).

Nesse sentido, a escola é também um lugar de imposições de modos de pensar, agir e sentir considerados como aptos a cada uma das pessoas que por ela transitam. Essa imposição possui a guarida de autoridade institucionalizada que é respaldada pelo saber acadêmico conferido a professoras e professores, operadores e operadoras educacionais. As atribuições distintas entre masculino e feminino circunscrevem-se na divisão política do trabalho, na vida privada e pública que auto se alimentam mutuamente. O currículo, os livros didáticos e atividades festivas como "dia das mães" e "dia dos pais", passando pelas festas e apresentações culturais como a confecção de "penacho"6 para as crianças no dia do índio, não só domesticam como indicam passividade e conformidade perante tais questões como, principalmente, garantem a heteronormatividade compulsória, ao invés de, no mínimo, ser realizado pela escola o debate histórico, político e emancipador.

Considerar a experiência escolar como fundamental para se promover a cultura do reconhecimento das pluralidades e dos comportamentos destoantes parece ser uma saída produtiva e qualitativa ao enfrentamento das desigualdades, por isso a importância de se discutir a educação escolar por meio das problematizações das relações de poder e hierarquias sociais opressoras. Desenvolver um olhar capaz de romper as práticas excludentes e que garantam a reflexão sobre o acesso e a permanência de todas/os as/os alunas/os é avivar a cidadania dentro dos limites da ética e dos direitos humanos, proporcionando que as diferenças sejam respeitadas em suas singularidades, deixando de serem usadas como critério para a discriminação, exclusão social e política.

\section{CONSIDERAÇÕES FINAIS}

Se desejamos uma escola melhor, isto é, democrática, com maior participação da comunidade escolar, com qualidade de ensino e que não atenda apenas aos interesses da elite dominante, mas de toda a população que dela precise, necessitamos primeiro (re)fazer o conceito de desigualdade construído e gestado pelos interesses do capital. É necessário que se desvincule a manutenção e fortalecimento de discriminações

\footnotetext{
${ }^{6}$ A palavra "penacho" aqui descrita, refere-se a um conjunto de penas utilizado nas aulas de artes do Ensino Fundamental, em comemoração ao 19 de abril, dia do índio.
} 
principalmente de raça, gênero e orientação sexual como mantenedores das diferenças distribuídas e ancoradas em extremos opostos. A educação é constituída de contradições e, consequentemente, por conflitos sociais, sendo assim, questionar a escola e a sua reprodução das desigualdades sociais e hierarquias polarizadas é desenvolver compromisso político e ético na garantia de direitos legais e práticas docentes humanizadoras.

A educação é terreno fértil para o enfrentamento às variadas formas de discriminação e violências, encontramos na escola caminhos para desconstruir a lógica tradicional de hierarquização dos saberes. Neste sentido, o ensino, como prática de fortalecimento e emancipação não linear de conhecimentos, colabora para uma sociedade mais justa e afirmativa em relação às desigualdades. Uma escola em que as diferenças são tratadas como positivas, toda a sociedade ganha, pois novas possibilidades são criadas como, por exemplo, a valorização da cidadania e o comprometimento diário com a solidariedade.

Para concluir, precisamos lembrar que estamos vivendo e sofrendo as consequências dos retrocessos disparados pelo golpe em nosso país. Em tempos de escola sem partido (sic), garantir ambiente seguro e fortalecedor para alunas/os e professoras/es é tarefa diária, porém, essa lição de casa deve ser realizada também nas universidades, na formação de docentes e na tessitura das nossas pesquisas. O golpe à democracia é golpe aos direitos humanos, por isso nossa resistência precisa ser traçada na feitura de nossas escritas, na solidez da nossa militância e na ética do nosso cotidiano.

\section{REFERÊNCIAS}

ALVIM, Mariana. Homofobia mata uma pessoa a cada 25 horas; Norte tem maior índice. Levantamento anual mostra recorde no país em 2016. O Globo, São Paulo, 24 jan. 2017. Disponível em:< https://oglobo.globo.com/sociedade/homofobia-mata-umapessoa-cada-25-horas-norte-tem-maior-indice-20819002> . Acesso em: 23 de nov. 2018.

ARROYO, Miguel. Políticas Educacionais e desigualdades: à procura de novos significados. Educ. Soc., Campinas, v. 31, n. 113, p. 1381-1416, out.-dez. 2010 Disponível em http://www.cedes.unicamp.br . Acesso em: 25 de ago. 2018. Bibliografia: p. [109]-113.

BONZANINI, LC., and BASSOI, TS. Os professores e o ensino de frações no $2^{\circ}$ ciclo do ensino fundamental. In: BRANDT, CF., and MORETTI, MT., orgs. Ensinar e aprender matemática: possibilidades para a prática educativa [online]. Ponta Grossa: Editora UEPG, 2016, pp. 145-159. ISBN 978-85-7798-215-8.

BOURDIEU, Pierre. A distinção: crítica social do julgamento. Tradução Daniela Kern; Guilherme J. F. Teixeira. São Paulo: Edusp; Porto Alegre, RS: Zouk, 2007. 
BOURDIEU, Pierre. A dominação masculina. Rio de Janeiro: Bertrand Brasil, 1999.

BRASIL. Ministério da Educação. Lei no 9.394, de 20 de dezembro de 1996. Estabelece as Diretrizes e Bases da Educação Nacional. Brasília, DF: MEC, 1996. Disponível em:< http://www.planalto.gov.br/ccivil 03/Leis/L9394.htm> . Acesso em: 8 ago. 2018.

CAVALLEIRO, Eliane dos Santos. Do silêncio do lar ao silêncio escolar: racismo, preconceito e discriminação na educação infantil. - 6ª . Ed., 3ª reimpressão. - São Paulo: Contexto, 2017.

DINIZ, Pedro. Brasil patina no combate à homofobia e vira líder em assassinatos de LGBTs. Folha de São Paulo, São Paulo, 17 mai. 2017. Disponível em:< http://www1.folha.uol.com.br/cotidiano/2017/05/1884666-brasil-patina-no-combate-ahomofobia-e-vira-lider-em-assassinatos-de-lgbts.shtml> . Acesso em: 10 set. 2018.

MIGUEL, Luis Felipe. Desigualdades e democracia: 0 debate da teoria política/organização: Luis Felipe Miguel. - 1 ed. - São Paulo: Editora Unesp, 2016.

MOCHI, Luciene Celina Cristina; LEITE, Lucimar da Luz. Gênero e violência de gênero no ambiente escolar - o estereótipo posto em questão: dos corredores às salas de aula. Observatório de violência de gênero: entre políticas públicas e práticas pedagógicas. /Crishna Mirella de Andrade Correa, Eliane Rose Maio (organizadoras). - Curitiba: CRV, 2015.

PERES, Milena Cristina Carneiro; SOARES, Suane Felippe; DIAS, Maria Clara. Dossiê sobre lesbocídio no Brasil: de 2014 até 2017. - Rio de Janeiro: Livros Ilimitados, 2018. 116 p.: il. (algumas color.) ; 21 cm. ISBN 978-85-63194-85-5

ROSSI, Marina. Seis brasileiros concentram a mesma riqueza que a metade da população mais pobre. El País, São Paulo, 25 set. 2017. Desigualdade Social. Disponível em: https://brasil.elpais.com/brasil/2017/09/22/politica/1506096531 079176.html Acesso 24 de nov. 2018.

SAVIANI, Dermeval. Pedagogia histórico-crítica: primeiras aproximações. 8. ed. Campinas, SP: Autores Associados, 2003.

SCOTT, Joan W. Gênero: uma categoria útil de análise histórica. Educação e Realidade, Porto Alegre, v. 20, n. 2, p. 72-99, jul. /dez. 1995.

SCOTT, Joan W. O enigma da igualdade. Revista Estudos Feministas, Florianópolis, v. 13 , n. 1, p. 11, jan. 2005. ISSN 1806-9584. Disponível em: <https://periodicos.ufsc.br/index.php/ref/article/view/S0104-026X2005000100002/7778>.

Acesso em: 25 nov. 2018.

SEN, Amartya. Desigualdade Reexaminada. Rio de Janeiro: Record, 2001.

SILVA, Tadeu Tomaz da. A produção social da identidade e da diferença. In: SILVA, T. T. da; HALL, S.; WOODWARD, K. (Org.). Identidade e diferença: a perspectiva dos estudos culturais. 13. ed. Petrópolis, RJ: Vozes, 2013. p. 7-72.

SPOSATI, A.; KOWARICK, L. (Ed.). O debate com Serge Paugan. Por uma sociologia da exclusão social. São Paulo: EDUC, 1999. 